\title{
Penerapan Sistem Informasi Presensi Mahasiswa Menggunakan Fingerprint Berbasis Web
}

\author{
Vita Octa Wihana ${ }^{\mathrm{a}, 1,{ }^{*}}$, Fikri Amrullah ${ }^{\mathrm{a}, 2}$ \\ ${ }^{a}$ Fakultas Teknologi Informasi, Universitas Merdeka Malang, Indonesia \\ 1 vitaoctawhn21@gmail.com ; ${ }^{2}$ fikri@unmer.ac.id \\ * corresponding author
}

ARTIKEL INFO

Article history

Diterima: 3 Juni 2019

Direvisi: 30 Juli 2019

Diterbitkan: 30 Agustus 2019

Keywords

Sistem Informasi

Fingerprint

Web

\section{ABSTRAK}

Presensi yang diterapkan di Fakultas Teknologi Informasi masih menggunakan lembar kertas yang ditanda tangani oleh setiap mahasiswa hal ini sangat tidak efisien dan membuat mahasiswa tidak disiplin. Dengan diterapkannya sistem presensi menggunakan fingerprint berbasis web memudahkan mahasiswa melakukan absen dan mencegah adanya manipulasi yang dilakukan mahasiswa dan admin dapat melakukan kontroling diluar area fakultas, hasil laporan absensi bisa berupa hasil real termasuk jam berapa mahasiswa terlambat absen atau tidak melakukan absen. Program ini menggunakan bahasa pemograman PHP dan SQL yang dapat menjadi alat bantu rekapitulasi kehadiran mahasiswa. Sistem ini dapat dikembangkan lagi untuk keperluan selanjutnya dapat ditambahkan data berupa jadwal kuliah dan data absen dosen maupun staff karyawan yang ada di Fakultas Teknologi Informasi.

\section{PENDAHULUAN}

Kesuksesan sistem informasi sangat perlu untuk diukur apakah penggunaannya sudah sukses diterapkan atau belum. Menurut penelitian terdahulu bahwa kesuksesan sistem informasi diukur dari seberapa besar pengguna akhir merasakan kepuasan terhadap penggunaan sistem informasi [1][2]. Demikian juga dengan penggunaan sistem informasi presensi mahasiswa dengan menggunakan fingerprint berbasis web. Sistem Presensi yang diterapkan di Fakultas Teknologi Informasi Universitas Merdeka Malang masih menggunakan cara manual dengan menggunakan lembar absensi yang kemudian di tanda tangani. Hal ini mempunyai banyak resiko kecurangan dan kesalahan dalam penginputan data yang dilakukan dosen ataupun mahasiswa. Mahasiswa adalah individu yang sedang menuntut ilmu pada tingkatan perguruan tinggi, di perguruan tinggi negeri maupun swasta atau lembaga lain yang setingkat. Tingkat intelektualitas yang tinggi, kecerdasan dalam berpikir dan kerencanaan dalam bertindak, berpikir kritis dan bertindak cepat dan tepat merupakan sifat yang cenderung melekat pada setiap mahasiswa [3].

Penerapan adalah mempraktekan atau cara melaksanakan sesuatu berdasarkan teori. Sistem informasi manajemen adalah sistem yang mepunyai alur tertentu yang diawali dari input hingga berubah menjadi output berupa informasi yang memberikan manfaat. Fingerprint sistem yang mengandung elemen-elemen fisik berupa perangkat keras, database,prosedur dan personalia pengoperasian. Dalam sistem ini menggunakan bahasa program PHP yang artinya singkatan dari Personal Home Page merupakan bahasa skrip yang tertanam dalam HTML untuk dieksekusi bersifat server side [4]. Sistem ini juga menggunakan database SQL yang digunakan untuk menyimpan informasi kedalam data, membuat struktur data,menulis program dalam bahasa PHP.

Penelitian sejenis oleh Elisabeth Febrina Tuto Burak Lamatoka (2016), Program Studi 
Teknik Informatika Universitas Sanata Dharma Yogyakarta, yang berjudul " Sistem Presensi Mahasiswa Berbasis Web Menggunakan Fingerprint Scanner (Study Kasus Program Studi Teknik Informatika Universitas Sanata Dharma Yogyakarta)" dengan menggunakan bahasa program PHP dan MySQL.

Kemudian sejenis oleh Ihsan Verdian (2015), Program Studi Ilmu Komputer Universitas Putra Indonesia YPTK Padang, berjudul Aplikasi Sistem Absensi Mahasiswa Menggunakan Sidik Jari Pada Universitas Putra Indonesia YPTK Padang, menggunakan bahasa program Visual Basic 6.0 dan MS Access, MS Excel dan SDK. Sistem presensi mahasiswa berbasis web ini dapat dikontrol oleh admin diluar jaringan local Fakultas Teknologi Informasi. Hasil dari laporan dapat dicetak langsung melalui aplikasi yang disediakan oleh mesin fingerprint.

\section{METODE}

\section{SDLC (Software Development Life Cycle)}

Penyusunan menggunakan metode SDLC yang menggunakan pengembangan pada model Waterfall. Model waterfall bersifat sistematis dan berurutan dalam membangun perangkat lunak.

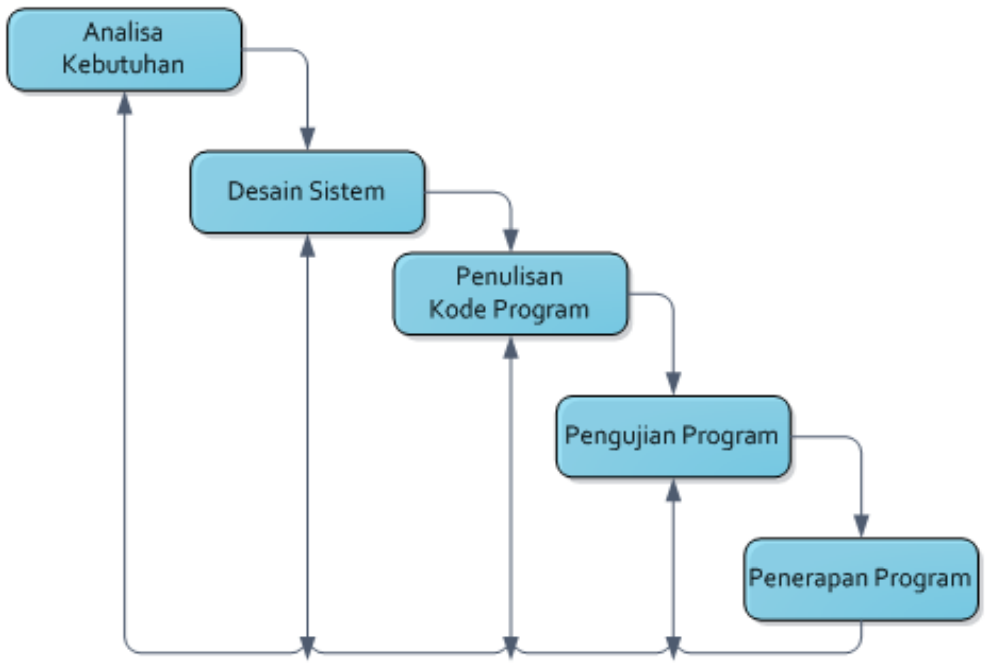

Gambar 1. Alur Penelitian

\section{Flowchart Sistem}

Flowchart adalah aliran data dari masuk sampai keluar menggunakan prosedur tertentu dan merupakan representasi dari pemrosesan aliran transaksi organisasi yang memuat sistem dan prosedur transaksi [5]. Flowchart (bagan alir) merupakan sebuah gambaran dalam bentuk diagram aliran dari algoritma-algoritma dalam suatu program, yang menyatakan arah alur program tersebut [6].

\section{DFD (Data Flow Diagram)}

DFD merupakan salah satu alat untuk mendokumentasi proses sistem yang fokus pada fungsi pada sistem dengan cara menggunakan informasi yang tersimpan kemudian memindahkan informasi/data antar fungsi dalam sistem. Data Flow Diagram (DFD) adalah suatu model logika data atau proses yang dibuat untuk menggambarkan dari mana asal data dan kemana tujuan data pada sistem tersebut, dimana data di simpan, proses apa yang menghasilkan data tersebut, dan interaksi antara data yang tersimpan dan proses yang dikenakan pada data tersebut [7]. 


\section{PEMBAHASAN}

Penelitian ini Sistem Presensi menggunakan fingerprint berbasis Web merupakan aplikasi untuk mempermudah mahasiswa dalam melakukan presensi dengan waktu yang akurat dan memudahkan admin yang ditugaskan dalam kotroling mahasiswa sehingga kesalahan saat melakukan absen ataupun manipulasi bisa dihindari. Hasil dari design program:

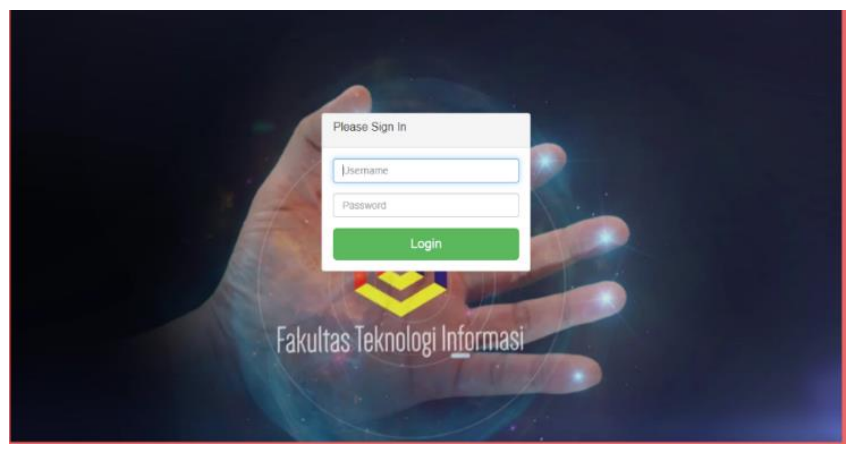

Gambar 2. Desain Login

Desain login pada Gambar 2 digunakan untuk menginput username admin dan password untuk masuk kedalam web sesuai yang dimiliki admin yang bertugas.

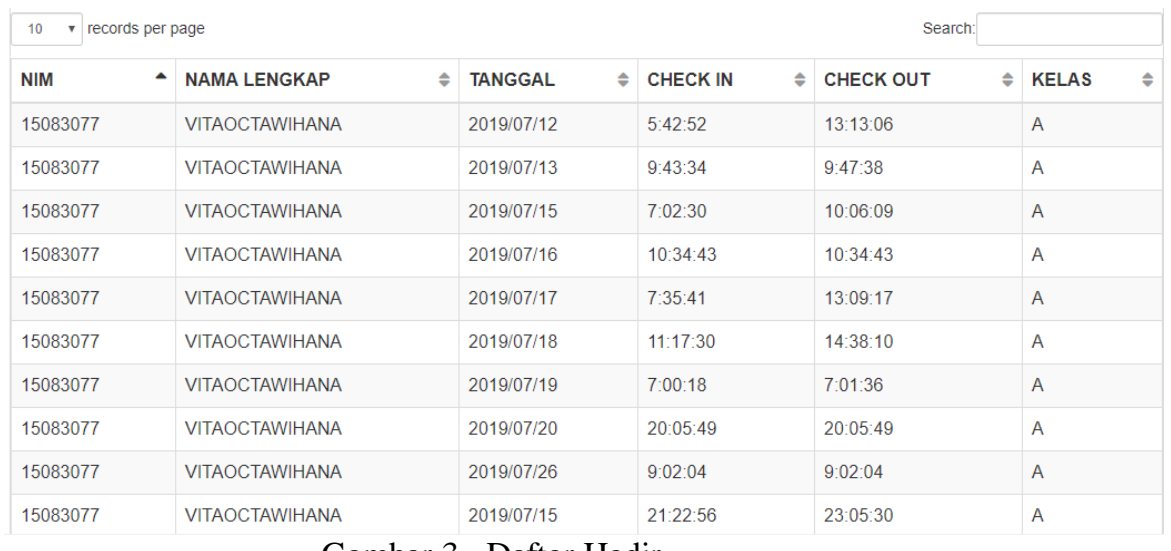

Gambar 3. Daftar Hadir

Daftar hadir yang ada di web digunakan untuk kontroling mahasiswa yang mulai masuk dan keluar.

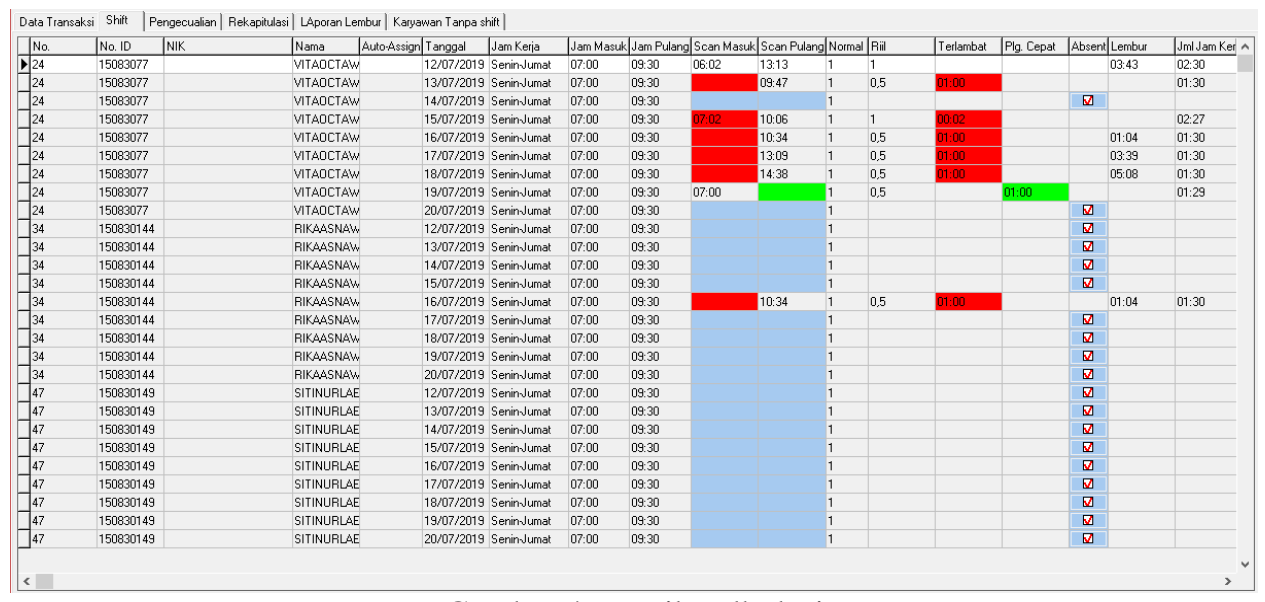

Gambar 4. Hasil Kalkulasi 
Hasil kalkulasi diperoleh dari aplikasi fingerprint dihasil kalkulasi terdapat hasil dari jam berapa mahasiswa memulai absen dan mengakhiri absen dihasil ini juga dapat diketahui jam berapa mahasiswa terlambat atau tidak melakukan absen.

\section{KESIMPULAN}

Dari Hasil penelitian yang telah dilakukan maka dapat disimpulkan: 1) Sistem dapat memudahkan mahasiswa dalam melakukan absensi dengan realtime. 2) Sistem memudahkan admin dalam mengelola data absen,menginput data dan melakukan kontroling mahasiswa diluar area fakultas. 3) Sistem ini dapat mendisiplikan mahasiswa. Saran yang diberikan untuk kegunaan pengembangan sistem selanjutnya antara lain : 1) Sistem ini dapat juga digunakan untuk Dosen dan Staff Pegawai lainnya. 2) Sistem ini belum adanya jadwal kuliah dari setiap kelas dan dosen yang mengajar pada waktu tertentu. 3) Sistem sebaiknya diunggah ke dalam hosting online, agar dapat digunakan oleh beberapa mesin fingerprint yang tidak berada 1 ip address. 4) Mengubah mesin fingerprint yang lebih kompetibel sesuai kebutuhan yang diinginkan dan support database yang sudah ada di fakultas. Untuk hasil cetak laporan realtime masih harus dilakukan di area local dan diakses melalui mesin fingerprint dengan kalkulasi hal tersebut menjadikan admin hanya bisa mengontrol jam masuk dan jam keluar mahasiswa saja saat berada di luar fakultas. Oleh karena itu sebaiknya mengganti mesin yang mendukung kebutuhan dan menambahkan kriteria laporan yang sesuai di dalam Web.

\section{REFERENSI}

[1] Andarwati, Mardiana dan Jatmika, Dodik. 2017. Analisis Pengaruh Kualits Sistem Informasi Akuntansi Terhadap Penerimaan Teknologi di Sektor UKM dengan Pendekatan Model TAM. Seminar Nasional Sistem Informasi (SENASIF), 1(1) hal.946-956

[2] A. Andarwati, Mardiana; Nirwanto, Nazief; Darsono JT. 2018. Analysis of Factor Affecting The Succes of Accounting Information Systems Based on Informtion technology on SME Managementsas Accounting InformationEnd User. EJEFAS Journal. p.97-102

[3] Arya Gandhi, M. 2017. Penerapan Absensi Finger Print Dalam Mendisiplinkan Kerja Pegawai Di Sekolah Menengah Kejuruan (SMK) Sekolah Menengah Tekhnik Industri (SMTI) Bandar Lampung.Skripsi.Universitas Islam Negeri Raden Intan Lampung.

[4] Budiman. 2006, Penelitian Bidang Sistem Managemen di Indonesia

[5] Irawan, A. Presensi Sidik Jari (Fingerprint) Berbasis Web Service.Jurnal Prosiding Seminar Sains dan Teknologi FMIPA Unmul Vol. 1 No. 1 September 2015, Samarinda, Indonesia

[6] Irwin N. 2011 .Sistem Informasi Penerimaan Siswa Baru Berbasis Web Dengan Php dan Sql.Skripsi. Universitas Negeri Yogyakarta.

[7] Nirwanto, Nazief dan Andarwati, Mardiana. 2019. End-user Satisfaction as asn Impact of The System Quality, Information Quality, and Top Management Support The Perceived Usefulness of Technology Utilization. Journal of Marketing Development and Competitiveness. 13(1), p.59-75 